\title{
As histórias de vida e a configuração dos gêneros jornalísticos: o caso da série "Gente de São José"
}

\author{
Life Stories, mixed category in the realm of journalistic genres: the example of the \\ series "People of St. Joseph" \\ Francisco de Assis ${ }^{1}$ \\ (francisco@assis.jor.br) \\ http://dx.doi.org/10.5216/cei.v15i1.22497
}

\begin{abstract}
Resumo
O trabalho discute as histórias de vida como categoria constitutiva de gêneros jornalísticos, demonstrando que elas estão a serviço de, pelo menos, duas classes de textos comumente praticadas pelos profissionais da área: o jornalismo interpretativo e o jornalismo diversional. Para tratar disso, utilizamos como pano de fundo a série "Gente de São José", publicada pelo jornal Valeparaibano (editado em São José dos Campos, SP, Brasil), de 2 a 25 de abril de 2009. Nossa reflexão procura agendar um aspecto importante para o entendimento dessa dinâmica: o papel singular do jornalista $\mathrm{e}$ de sua percepção sobre o mundo e sobre os personagens que o rodeiam. Trata-se de estudo de caso, que se vale de técnicas diversas, como pesquisa documental e entrevista semiestruturada. Ao término do percurso analítico, anotamos algumas considerações - não conclusivas - que nos indicam elementos subjetivos, mas coerentes ao processo de elaboração do jornalismo, notadamente influentes nas decisões e nas escolhas que resultam no trabalho publicado pela imprensa.
\end{abstract}

Palavras-chave: Histórias de Vida. Gêneros Jornalísticos. Jornalismo Diversional. Jornalismo Interpretativo. Série Gente de São José.

\begin{abstract}
The paper discusses the life stories as constitutive category of journalistic genres, showing that they are serving at least two classes of texts commonly practiced by professionals: the interpretive journalism and journalism diversional. We use as a backdrop the example set by the series "People of St. Joseph," published by the newspaper Valeparaibano (edited in São José dos Campos, SP, Brazil), from 2 to 25 April 2009. Our reflection demand schedule an important aspect to understanding this dynamic: the unique role of the journalist and his perception of the world and the characters that surround him. This is a case study, which uses various techniques, such as semistructured interviews and documentary research.
\end{abstract}

Keywords: Life Stories. Journalistic Genres. Diversional Journalism. Interpretive Journalism. Celebrity Series of St. Joseph.

\section{Introdução}

\footnotetext{
${ }^{1}$ Professor do curso de Jornalismo da Escola Superior de Propaganda e Marketing (ESPM). Doutorando e Mestre em Comunicação Social pela Universidade Metodista de São Paulo (Umesp). Vice-coordenador do grupo de pesquisa (GP) Gêneros Jornalísticos, da Sociedade Brasileira de Estudos Interdisciplinares da Comunicação (Intercom).
} 
As histórias de vida - de famosos ou de anônimos - conquistam espaço na imprensa por uma série de razões: geram identificação junto ao púbico-leitor, ajudando-o a se encontrar nas muitas situações que se apresentam a ele; trazem à tona experiências interessantes e importantes de serem compartilhadas; personificam assuntos os mais diversos; fazem saber quem são os atores da cena noticiosa; ou, simplesmente, chamam a atenção pela própria história revelada.

Processo social, o jornalismo depende das pessoas - e de suas vidas - para ter vida própria. Não há jornalismo sem gente, sem falas, sem percepções cotidianas a serem registradas. A relação entre esses elementos é visivelmente necessária para que os veículos jornalísticos sobrevivam principalmente nas situações em que estes se veem obrigados ou motivados a fazer a oferta de conteúdos que ultrapassem as barreiras características das produções subordinadas a mediações institucionais, empresariais e/ou governamentais.

Isto posto, nossa intenção, aqui, é situar essa categoria na esfera dos gêneros jornalísticos, demonstrando que ela está a serviço de, pelo menos, duas classes de textos comumente praticadas pelos jornalistas: o jornalismo interpretativo e o jornalismo diversional. Nossa discussão parte do modelo classificatório norteador de todas as pesquisas que realizamos a respeito dessa questão, ou seja, a proposta de José Marques de Melo (2010: 2006a; 2006b).

Por percebermos a singularidade das histórias de vida, chegamos a cogitar, em trabalho anterior (ASSIS, 2008), que elas poderiam se constituir como formato autônomo do jornalismo diversional. Porém, revisando bibliografias específicas, retomando criticamente as definições dadas por Marques de Melo aos formatos desse gênero - história de interesse humano e história colorida , bem como acompanhando fenômenos e situações que se originam na própria prática do jornalismo, notamos que o relato sobre trajetórias de vida - ou sobre parte importante desse caminho - consiste em elemento que se manifesta tanto no jornalismo diversional - nas histórias de interesse humano - quando no jornalismo interpretativo - nos perfis.

A fim de avançar na questão, propusemo-nos, aqui, a analisar um exemplo que bem caracteriza aquilo que queremos discutir: a série "Gente de São José", publicada pelo jornal Valeparaibano, de 2 a 25 de abril de 2009, tendo sido formada por oito textos que ocuparam sempre uma página inteira do standard (textos extensos, portanto). Produzida pela jornalista Isabela Rosemback - também sua idealizadora -, a série relata as histórias de vida de oito personagens residentes em São José dos Campos, cidade de mais de 600 mil habitantes, situada na região do Vale do Paraíba (interior do Estado de São Paulo, Brasil). 
Seus textos não seguem o padrão tradicional da notícia ou da reportagem. Com características textuais próximas da literatura, seriam, em linhas gerais, típicos elementos do jornalismo diversional. Todavia, foram denominados, pela equipe editorial, como perfis. É aí que vislumbramos um cenário propício para aprofundar nossas reflexões, a partir dos seguintes objetivos: a) discutir as nomenclaturas adotadas pela proposta taxionômica e pelos profissionais atuantes no mercado; b) rever a localização das histórias no domínio dos gêneros jornalísticos; c) observar e analisar como e em que situações os jornalistas e os veículos se ocupam dessa categoria.

A natureza do estudo qualitativa. É importante esclarecer que, embora observemos as características dos textos que compõem a série, nossa análise não se fixou no conteúdo. O percurso metodológico compreende, principalmente, as entrevistas realizadas com a repórter Isabela Rosemback e a utilização do material publicado como fonte documental. Trata-se, portanto, de estudo de caso, nos moldes sugeridos por Robert K. Yin $(2005 \text {, p. } 32)^{2}$, os quais foram revisitados por Marcia Matsuchi Duarte (2005, p. 215-218).

\section{Gêneros jornalísticos: apontamentos essenciais}

Se há, no jornalismo, aspecto passível de contradições e que não faz enxergar possibilidade de um consenso definitivo, ele diz respeito aos gêneros e aos formatos que essa atividade incorpora. Primeiro porque, como observado por alguns estudiosos, a noção de gênero nem sempre aparece clara na bibliografia específica sobre o jornalismo (BONINI, 2003, p. 209). Em segundo lugar, porque os autores - e isso tomando como parâmetro apenas os mais reconhecidos como fontes confiáveis - não se pautam pelos mesmos critérios de identificação, classificando as produções e os produtos da imprensa de maneira bem diferente uns dos outros.

Como utilizamos este espaço para tratar de um mote específico e, mais do que isso, discutir um caso único, não cabe - nem é necessário - uma discussão mais ampla sobre os fundamentos que norteiam os gêneros jornalísticos. Por isso, acreditamos ser mais vantajoso partirmos diretamente para a observação do modelo classificatório que nos orienta, sinalizando os aspectos fundamentais para seu entendimento.

\footnotetext{
${ }^{2}$ Diz Yin (2005, p. 32): "Um estudo de caso é uma investigação empírica que investiga um fenômeno contemporâneo dentro de seu contexto da vida real, especialmente quando os limites entre o fenômeno e o contexto não são claramente definidos". E acrescenta, mais adiante: "baseia-se em várias fontes de evidências, com os dados precisando convergir" (YIN, 2005, p. 33). Compreendemos, portanto, que se trata de tipo de estudo que aceita múltiplas técnicas, as quais vão sendo escolhidas e definidas conforme o fenômeno vai sendo apreciado. É o que buscamos fazer, amparando-nos, principalmente, na entrevista, "considerada uma das mais importantes fontes de informações para um estudo de caso" (DUARTE, 2005, p. 230).
} 
Antes de tudo, vale esclarecer que tal proposta, sistematizada em materiais didáticos (MARQUES DE MELO, 2006a: 2006b), em textos avulsos (MARQUES DE MELO, 2010; 2011) e em livro coletivo (MARQUES DE MELO \& ASSIS, 2010) pressupõe que o jornalismo se organiza a partir de cinco gêneros: informativo, opinativo, interpretativo, diversional e utilitário. De todos, interessa, nesta abordagem, observar mais atentamente os gêneros interpretativo e diversional, por serem classes com as quais as histórias de vida dialogam muito bem, conforme já indicamos.

Há certa confusão, por parte de profissionais e de pesquisadores, com relação ao jornalismo interpretativo. Tem-se, pelo senso comum, que qualquer texto maior do que uma notícia é interpretativo, fato que levam muitos a caracterizar a reportagem como tal. Todavia, a interpretação, por si, não constitui o gênero, até mesmo porque a produção de diferentes gêneros pressupõe interpretar os fatos cotidianos - como, por exemplo, o jornalismo opinativo, uma vez que não há meios de avaliar um acontecimento sem interpretá-lo. Especificamente, o gênero interpretativo deve ser entendido como sinônimo de "explicativo", uma vez que sua função é apresentar elementos que exponham o contexto do fato trabalhado jornalisticamente, resgatando antecedentes, esmiuçando aspectos atuais e fazendo projeções futuras (NAVA, 1996, p. 9-10).

Nesse cenário e conforme a classificação de Marques de Melo (2006a, grifo nosso), encontra-se o formato perfil, o qual, segundo ele, é o "relato biográfico sintético" que identifica os “"agentes' noticiosos” e “focaliza os protagonistas mais freqüentes da cena jornalística, incluindo figuras que adquirem notoriedade ocasional". Vê-se, portanto, que é o texto destinado a mostrar quem é quem, mas sem delongas ou aprofundamentos; serve tão somente para apresentar dados essenciais do personagem que, em determinado momento, merece atenção da imprensa, ajudando a entender sua inserção em dado cenário.

$\mathrm{Na}$ outra ponta, o gênero diversional, não muito diferente do anterior, também é objeto de confusões e de contradições. A começar pelo fato de sua estrutura - o jornalismo elaborado com técnicas de escrita oriundas da literatura - ser comumente identificada pela nomenclatura “jornalismo literário", muito embora o significado desse último termo traga, em si, algumas especificidades no tocante à produção e à percepção do objeto que nem sempre são identificáveis naquilo que jornais e revistas costumam produzir.

De todo modo, tem-se que se trata do gênero legitimado por caminhar na contramão do propósito puramente informativo. É, em essência, o jornalismo que revela o diferente, que é capaz de humanizar os relatos, tornando-os atraentes aos olhos de potenciais leitores. Não por menos, um 
de seus formatos é rotulado como história de interesse humano, "narrativa que privilegia facetas particulares dos 'agentes' noticiosos”, no dizer de Marques de Melo (2006a), que ainda sintetiza:

Recorrendo a artifícios literários, emergem dimensões inusitadas de protagonistas anônimos ou traços que humanizam os "olimpianos". Apesar da apropriação de recursos ficcionais, os relatos devem primar pela "verossimilhança" sob o risco de perder a "credibilidade". Destina-se a preencher os espaços ociosos dos aficionados por relatos jornalísticos.

A diferença dessa classe de textos encontra-se, justamente, na sua disposição em abrir espaço para a criatividade. Em países de língua hispânica, por exemplo, a nomenclatura que recebe não é "diversional" nem tampouco "literário", mas, sim, "criativo" ou "de criação" (BERNAL \& CHILLÓN, 1985). Por esse motivo, podemos dizer que sua inserção no espaço jornalístico se dá pela soma de dois aspectos: a identificação de pautas interessantes e o tratamento diferenciado dado a elas - sim, pois um episódio atraente, que se sobressai em meio ao cotidiano, não precisa necessariamente ser contado com feições literárias, criativas. É isso o que parece ocorrer com as histórias de vida.

\section{Histórias de vida: algumas considerações}

Assim como não há grandes acordos em relação aos gêneros jornalísticos, em sentido largo, também encontramos divergências na classificação dos relatos sobre a vida de pessoas. Há autores, por exemplo, que fazem distinções entre biografias, perfis e histórias de vida (GOBBI, 2005, p. 85), sendo que as particularidades de cada tipo são definidas tanto pelo tamanho do texto quanto pelos enfoques. As biografias, por exemplo, seriam trabalhos mais completos, que dão conta de mostrar toda a trajetória de algum sujeito; já o perfil seria um formato mais sucinto, focado em características específicas do personagem, as quais servem para entender de quem se trata ou, até mesmo, sua personalidade; as histórias de vida, por sua vez, estariam mais fixadas em alguns momentos da vida de uma pessoa.

Sergio Vilas Boas (2003, p. 16-17) afirma que a expressão "histórias de vida" é mais abrangente que as demais, tendo emergido "no contexto das pesquisas qualitativas em Ciências Sociais (sociologia, antropologia, história, psicologia)". E vai além, ao dizer que "essa modalidade dá atenção total ou parcial às narrativas sobre as vidas de indivíduos ou de grupos sociais, visando humanizar um tema, um fato ou uma situação contemporânea”. 
Em trabalho mais recente, o autor retoma essa polifonia que se constitui como uma das marcas da categoria aqui evocada, e explica:

O sociólogo Norman Denzin oferece conceitos sucintos para biografia, autobiografia, histórias de vida, narrativa de vida, história oral, história pessoal e muitos outros nomes que tanto podem ser coincidentes quanto conflitantes, conforme o contexto em que são empregados. Todo esse grupo de variados métodos (ou atitudes, ou visões de mundo) da pesquisa biográfica e autobiográfica em Ciências Sociais está sujeito a convenções que estruturam a maneira como vidas têm sido escritas. (VILAS BOAS, 2008, p. 21).

Concordamos com a ideia de que a definição de nomenclaturas e de classificações se dá por conveniências estabelecidas de acordo com áreas, grupo de autores, correntes de pensamento, etc. E essas anotações acabam se tornando tão dinâmicas quanto o fenômeno ao qual se reportam. O próprio Vilas Boas tem adotado, atualmente, as expressões "biografismo" e "escrita de vida" para identificar práticas da mesma natureza.

Muitas vezes, também, as terminologias são empregadas sem que haja interesse em especificá-las. É o caso do ensaio que Marli dos Santos (2009) escreveu a respeito da exploração das histórias de vida em grandes reportagens. Sua preocupação, no texto, é discutir a inserção dessas histórias como elementos constitutivos de um gênero, voltando o olhar especialmente para as técnicas que podem auxiliar a sua composição, tal como a história oral ${ }^{3}$. Na linha de raciocínio esboçada em sua discussão, ela demonstra entender as histórias de vida como algo resolvido e sem necessidade de ser discutida além do que a própria junção das palavras "história" e "vida" já pressupõe.

A abordagem de Santos (2009, p. 28) - que a certa altura afirma: "como narrativa da atualidade, o jornalismo também se preocupa com a aproximação da realidade, as histórias de vida falam muito mais que as estatísticas" - tem algo em comum com nosso trabalho. Assim como ela, também nós identificamos as histórias de vida como elemento que constitui determinadas formas jornalísticas. Não se trata, portanto, de um gênero ou de um formato autônomo, mas, sim, da essência que dá corpo a perfis ou a histórias de interesse humano - nosso foco - ou até a grandes reportagens caso diagnosticado pela autora.

\footnotetext{
${ }^{3}$ Metodologia utilizada, principalmente, em pesquisas históricas e sociológicas, surgiu como maneira de registrar acontecimentos recentes por meio da coleta de depoimentos das pessoas que os vivenciaram ou presenciaram. É uma maneira de valorizar a memória e as lembranças dos indivíduos que testemunharam a história recente. Caracteriza-se, entre outros fatores, pelo espaço praticamente indeterminado para que o depoente faça seu registro, ou seja, cada entrevistado tem liberdade para falar o quanto quiser a respeito de dado assunto, o que lhe permite explorar detalhes e oferecer dados mais precisos do que poderia revelar caso a entrevista fosse comprometida por limitações de tempo.
} 
É evidente que as histórias de vida são o teor de gêneros autônomos e de grande destaque, como são, por exemplo, as biografias. Mesmo estas, reconhecidas como obra específica não apenas por especialistas, são classificadas como "gênero híbrido", por estarem situadas "na fronteira entre história e literatura" e, ainda, pelo fato de passarem por uma "transformação de valorização e de representatividade como abordagem histórica e social", segundo Virginia Fonseca e Karine Vieira (2011, p. 103). Para elas, ainda,

o leitmotiv do gênero passou de problema a virtude. O contar a história a partir da trajetória de vida daqueles que a viveram já foi visto pela historiografia como um caminho pouco seguro, sob a perspectiva totalizante e estruturalista de que a busca por uma unidade do eu no relato biográfico se convertia em impossibilidade.

Não negando, portanto, a autonomia de gêneros relacionados exclusivamente ao contar de trajetórias humanas, retomamos nosso foco ao ponto de partida desta discussão, ou seja, a das histórias de vida como elemento que pode ser incorporado por gêneros diversos, mediante uma série de fatores e/ou de escolhas, como a série empreendida pelo jornal Valeparaibano ilustra, com bastante propriedade.

\section{A série "Gente de São José"}

Antes de darmos início às considerações específicas sobre o corpus que subsidia nossa discussão, faz-se necessário registrar algumas observações a respeito do que iremos tratar aqui:

a) escolhemos a série "Gente de São José" como foco desta reflexão por a considerarmos um exemplo interessante e com aspectos bastante expressivos, que ajudam a entender a complexidade do fenômeno que nos atrai para este exercício, ou seja, o das histórias de vida como elementos do jornalismo; todavia, não queremos, de modo algum, definir nosso objeto como amostra probabilística ou como espelho do todo; ele consiste em indicador de procedimentos que podem ser comuns a iniciativas similares, servindo, por isso mesmo, de parâmetro para a observação de outras experiências;

b) o Valeparaibano foi extinto em 2010, durante processo que resultou na sua transformação em revista ${ }^{4}$ e na criação de um novo diário - denominado $O$ Vale $^{5}$-, para substituí-lo, como empreendimento de parte dos sócios que detinham o controle do antigo veículo; no entanto,

\footnotetext{
${ }^{4}$ A revista é editada pela Empresa Jornal O Valeparaibano Ltda, a mesma que mantinha o jornal extinto. Circula, conforme informações disponibilizadas em seu website (http://www.valeparaibano.com.br), em mais de 40 cidades do Vale do Paraíba, Serra da Mantiqueira, Litoral Norte e Alto Tietê.

${ }^{5} \mathrm{O}$ site do jornal, lançado em 4 de abril de 2010, pode ser acessado neste endereço: http://ovale.com.br
} 
a reflexão sobre os processos que envolveram a série elaborada pela jornalista Isabela Rosemback não se inviabiliza pelo fato de o jornal não mais existir, já que se trata de caso específico, datado, a ser discutido como fenômeno isolado, muito embora não deslocado de tomadas de decisões e de procedimentos característicos da política editorial que norteava aquela publicação;

c) entendemos o processo de elaboração dos referidos textos como uma relação estreitamente articulada entre jornalista, jornal e fontes (no caso, os personagens que protagonizaram a série); por isso mesmo, trataremos, na sequência, da própria história de vida (focada especialmente no delineamento profissional) da autora dos textos, pois muitos elementos de sua constituição nos ajudam a entender o objeto em seu contexto.

Registradas essas especificações, podemos dar continuidade à descrição das principais evidências analisadas ao longo deste estudo de caso. E o faremos, como estratégia didática, em ordem cronológica.

\subsection{Os antecedentes}

Nascida em São José dos Campos, em 10 de julho de 1984, Isabela Rosemback é jornalista desde a adolescência. Não que tenha atuado nesse ramo mesmo antes da vida adulta. Mas suas primeiras experiências em fazer aquilo que iria praticar profissionalmente começaram já na década de 1990, com um passatempo: a elaboração de um jornalzinho de bairro, que relatava amenidades do cotidiano local e até mesmo estampava manchetes polêmicas, como os bochichos sobre o prédio velho que iria se tornar shopping center. E para elaborar a publicação artesanal, ela e as vizinhas da mesma faixa etária - suas primeiras "colegas de trabalho" - seguiam o percurso comum da atividade jornalística: entrevistavam moradores, escreviam textos, revisavam, imprimiam e distribuíam... A brincadeira era coisa séria.

Conforme os anos se passaram, os hábitos e os interesses da adolescente foram direcionando seu foco. Tanto é que a escolha definitiva pelo jornalismo como profissão ocorreu, segundo ela própria relata, em razão daquilo que chama de um "clichê" comum a muitos ingressantes no curso de graduação dessa natureza, ou seja, por conta do gosto mantido pela leitura e pela escrita. Mas não só. Queria ser escritora, é verdade. Porém, criar enredos não lhe parecia algo muito simples. Foi aí que notou uma alternativa, próxima aos seus interesses, mas fincada na vida real.

O tempo mostrou para Isabela que havia "um jeito bom para escrever": contar a história dos outros. "Os outros sempre têm uma história pra contar, e com certeza é sempre interessante, porque 
os outros são interessantes, embora algumas de suas histórias sejam tristes", acredita ela ${ }^{6}$. Foi assim, portanto e por esses motivos, que decidiu ingressar, em 2003, no curso de jornalismo da Universidade de Taubaté (Unitau), o qual concluiu em 2006.

Recém-formada, ela acorreu à capital paulista, no início de 2007, para galgar um novo estágio de formação: a pós-graduação lato sensu em Jornalismo Literário, oferecida pela Academia Brasileira de Jornalismo Literário (ABJL), cuja missão é "o desenvolvimento de metodologias e técnicas que possam contribuir para a melhoria da qualidade da reportagem na imprensa brasileira e para a formação de autores de narrativas de não-ficção", conforme indicado em seu website ${ }^{7}$.

A opção pelo novo curso não se deu por acaso. Ainda na graduação, Isabela acompanhou, ora de longe, ora de perto, a atuação dos professores e pesquisadores que mantêm a ABJL. Dos mais significativos contatos com aquele grupo, na época aludida, ela se lembra com especial apreço dos livros de Sergio Vilas Boas - autor nacionalmente reconhecido por suas incursões no terreno das escritas de vida, como já observamos no quadro teórico anteriormente descrito - e da participação em uma oficina ministrada por Edvaldo Pereira Lima, na Unitau, ocasião em que pôde acompanhar de perto as ideias que, até ali, só havia acompanhado por leituras próprias ou por releituras de professores da instituição em que se graduou. As ideias do professor palestrante, é bom destacar, são também as que subsidiam e norteiam a academia estruturada em torno do objeto que ele e outros denominam como jornalismo literário.

Os debates e os conteúdos apreendidos no período em que frequentou a ABJL influenciaram sua atuação dali pra frente. É claro que não só despertaram percepções totalmente novas. Muito do que viu e ouviu durante as aulas somaram-se aos interesses que ela já possuía, no tocante à profissão, como fazer do jornalismo um instrumento para dar voz às pessoas que têm algo novo ou interessante para dizer ou, então, elaborar textos que fujam da padronização do lead ou da estrutura engessada que configura a maioria das reportagens publicadas pela imprensa.

No curso de especialização, Isabela aprimorou o que chama de "escrita afetiva", texto "mais

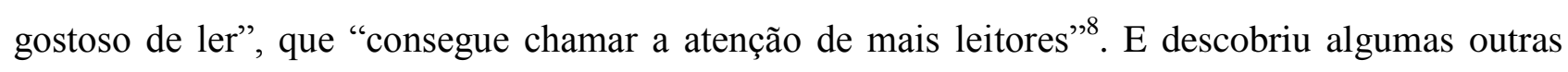
nuances e a novas possibilidades, como, por exemplo, a possibilidade de o jornalismo flertar com a história oral; a valorização da criatividade no processo de apuração e de elaboração de matérias; o

\footnotetext{
${ }^{6}$ Depoimento concedido ao autor em 8 de março de 2012.

${ }^{7}$ Disponível em: http://www.abjl.org.br.

${ }^{8}$ Termos extraídos do depoimento concedido ao autor em 8 de março de 2012.
} 
entendimento de que as percepções das pessoas sobre uma mesma situação ou sobre um mesmo cenário nunca são as mesmas.

Por essa época, a jornalista trabalhava no jornal Valeparaibano, diário que circulava de terça-feira a domingo, em cidades do Vale do Paraíba, da Serra da Mantiqueira e do Litoral Norte, muito embora seu principal alvo fosse São José dos Campos, município que, não por acaso, acolhia sua sede. Ali, onde ingressou como estagiária, a jovem fez quase tudo, o que inclui desde "rondas" - ligações a plantões policiais, com o objetivo de identificar as ocorrências registradas durante os plantões - até matérias de final de semana, cadernos especializados e o projeto “Gente de São José”, idealizado e executado por ela.

\subsection{0 início}

No trânsito de 2007 para 2008, Isabela Rosemback estava cursando os últimos módulos da pós em Jornalismo Literário, momento no qual os estudantes deveriam escolher um tema para a elaboração do trabalho de conclusão de curso (TCC). Foi aí que, unindo os pressupostos descobertos durante as aulas aos seus interesses - principalmente ao apreço pela experiência de pessoas comuns, aquelas que escondem histórias interessantes, ofuscadas, muitas vezes, pelo próprio cotidiano -, a ideia surgiu: elaborar uma série de textos sobre "humanos anônimos" - para fazer uso da expressão que Ricardo Kotscho (2011, p. 177) cunhou ao apresentar a obra de Eliane Brum, A vida que ninguém vê $\hat{e}^{9}$ e avaliar sua repercussão junto ao público-alvo do jornal.

Trabalhando no caderno "Bairro"10, eu me deparava com muitas [histórias de pessoas consideradas anônimas], e não tinha espaço para escrever tudo o que elas possibilitavam ou, então, não tinha nem como colocá-las ali. Foi o que começou a criar essa vontade em mim: o pouco espaço do "Bairro" para as histórias ótimas que eu descobria [...] A ideia inicial era fazer esses perfis e, então, fazer uma análise de como o público teria recebido isso ${ }^{11}$.

\footnotetext{
${ }^{9}$ A vida que ninguém vê é uma coletânea de textos que a jornalista Eliane Brum publicou no jornal Zero Hora, de Porto Alegre (RS), merecedor do Prêmio Jabuti 2007, na categoria Melhor Livro de Reportagem.

${ }^{10}$ O caderno "Seu Bairro" era um suplemento composto por editorias voltadas exclusivamente para o cotidiano das cidades de São José dos Campos, Taubaté e Jacareí. Foi lançado em julho de 2005, com a finalidade de ampliar o espaço para o jornalismo focado no interior dessas cidades. Ampliar porque, naquela ocasião, o Valeparaibano já publicava uma seção homônima, três vezes por semana, além da coluna diária "De olho na rua", na qual eram divulgadas pequenas notas com reclamações de moradores da região e respostas dos setores responsáveis pelos respectivos problemas.

${ }^{11}$ Depoimento concedido ao autor em 8 de março de 2012.
} 
A bem da verdade, o projeto do TCC não vingou como imaginado inicialmente. No entanto, os textos - aos quais ela dá o nome de "perfis", com o argumento de que se tratam de recortes sobre a trajetória dos personagens, sem a mesma profundidade exigida por uma biografia - foram elaborados e publicados de maneira seriada pelo Valeparaibano.

O processo teve início já no final de 2007, quando Isabela apresentou ao editor-chefe do jornal, Hélcio Costa, a proposta de escrever histórias de pessoas anônimas - talvez seis, sendo publicada uma por semana -, com características bem distintas dos textos comumente publicados por aquela folha. Em outras palavras, a sugestão era produzir matérias de página inteira, com número de caracteres muito superior ao que se costumava fazer, até mesmo quando se tratava de reportagens especiais de domingo, inseridas no reduzido espaço disponibilizado entre os anúncios publicitários.

A sugestão foi aceita, mas algumas negociações precisaram ser feitas, principalmente no que diz respeito ao número de textos e à ordem de publicação. Ficou definido, pelo editor-chefe, que seriam preparados oito textos - em vez de seis -, a serem divulgados duas vezes por semana - às quintas e sábados. A opção pela sequência bissemanal atendia a uma estratégia para atrair e fidelizar leitores: a preferência pela quinta se deu por ser um dia considerado de grande leitura, assim como é o domingo; porém, o segundo dia escolhido não foi o "principal" do final de semana, por ser a edição dominical espaço para matérias especiais, que poderiam "concorrer" com a série.

Não obstante o projeto tenha sido pensado entre o final de 2007 e o início de 2008, só foi levado a efeito no primeiro semestre do ano seguinte. Alguns contratempos, os quais não vêm ao caso, e a sobreposição de trabalhos mais urgentes fizeram com que fosse postergado. Com isso, a publicação ocorreu somente em abril de 2009.

\subsection{O desenrolar da(s) história(s)}

Retrocedendo um pouco no tempo, importa explicar que a identificação - e a consequente escolha - dos oito personagens se deu por razões diversas. Como já relatado, o olhar de Isabela começou a se voltar com mais atenção a esses anônimos na época em que cursava o lato sensu e, concomitantemente, era repórter do caderno "Seu Bairro". Por esses tempos, ela deu início a uma

\footnotetext{
${ }^{12}$ Um aspecto que também diferencia esse tipo de texto, conforme a percepção da jornalista - a qual, evidentemente, recupera pressupostos da $\mathrm{ABJL}$-, é que se trata de matéria mais baseada na percepção do jornalista a respeito dos sujeitos e nas declarações por eles concedidas, em detrimento de uma abordagem cronológica, que valorize a sequência de acontecimentos que teceram a trajetória dos sujeitos. Além disso, como já lembrado, os ditos perfis não se preocupam em registrar toda a história de uma vida; em vez disso, dedicam-se a traçar um panorama de quem é a pessoa e situações mais interessantes que marcaram sua existência.
} 
“coleção" de boas histórias, transformadas, mais tardes, em "minipautas", elaboradas em conformidade com um modelo aprendido nas aulas de jornalismo literário.

Em linhas gerais, a pauta preparada procurava responder, para cada sujeito, perguntas da seguinte ordem: "Por que eu quero escrever sobre essa pessoa?" ou "Onde eu quero chegar com esse texto?", entre outras semelhantes. De sua lista original, apenas uma pessoa foi excluída, pois a história mostrou-se inviável de ser apurada e relatada seguindo os mesmos parâmetros das demais. Além disso, outros nomes - para chegar aos oito números - foram selecionados, sendo um deles, inclusive, sugerido pelo editor, fato que nos reforça o pensamento de que a relação jornalista-jornalfonte é uma unidade indivisível na produção desse jornalismo que foge do "padrão do dia a dia".

A esta altura de nossa discussão, parece-nos oportuno apresentar os oito personagens que compuseram a série "Gente de São José”, identificando a maneira como a jornalista chegou até eles e os aspectos que procurou evidenciar. E o fazemos pela ordem de publicação ${ }^{13}$, que é praticamente a mesma ordem de realização das entrevistas e de redação dos textos, aproveitando para reproduzir os trechos iniciais de cada matéria ${ }^{14}$. Vejamos:

\section{Paulo César Fernandes, servidor público.}

Isabela chegou até ele quando atuava no "Seu Bairro", por intermédio de sua irmã, pesquisadora da área de Sensoriamento Remoto. Paulo foi indicado como fonte para falar sobre os logradouros de São José dos Campos, pois o caderno mantinha uma seção fixa que revelava as histórias de ruas, avenidas, parques, dentre outras vias públicas da cidade. Muito mais do que declarações de um especialista, seus relatos demonstraram o conhecimento de quem é movido pela curiosidade.

A abertura do texto protagonizado por ele ficou assim: "Todos os dias um curioso homem de 49 anos se esconde no galpão do Arquivo Público de São José dos Campos para encontros freqüentes com ilustres habitantes da cidade, em maioria já mortos. Apesar de sua mesa de trabalho ser bem em frente ao balcão de atendimento, sua figura magra e baixa parece ser

\footnotetext{
${ }^{13}$ A sequência dos textos, bem como seus títulos e suas respectivas datas de publicação, é a seguinte: "Paulo 'Dylan', colecionador de histórias" (02/04), "Lúcia Farias, ideologia e identidade" (04/04), "Youssef Elkhouri, homem de palavra" (09/04), "Simãozinho, a voz da "Porteira Sertaneja"” (11/04), "Xuxa, mulher de várias identidades" (16/04), "Lunático, o artista incompreendido" (18/04), "João dos Bichos, holandês da sorte" (23/04), "Dona Ceci, um retrato de fé" (25/04).

${ }^{14} \mathrm{O}$ projeto original já previa a inserção de um bloco de texto - com fonte diferenciada do restante - como abertura para cada página, que servisse como uma espécie de chamada para o que viria na continuação. E assim foi feito, com uma ou outra adequação.
} 
engolida pela amplidão do ambiente - um antigo armazém com pé direito alto, tomado pelo silêncio constrangedor típico das salas de estudos e das bibliotecas”.

II. Maria Lúcia Fér Farias, empresária.

É uma das personas que não constava no projeto original. Foi indicada por um jornalista do próprio Valeparaibano, que a entrevistou para uma matéria com outro foco, na época em que Isabela já estava se articulando para preparar a série. O fator "interesse" recaiu sobre o fato de a empresária ter sido militante no período de ditadura militar (1964-1985).

As primeiras palavras do texto ao qual dá vida são as seguintes: "Em uma foto de quando tinha 20 anos, com os cabelos altos e impecavelmente penteados ao estilo dos anos 1960, a empresária Maria Lúcia Fér Farias sorri em preto e branco em um lugar qualquer de Salvador (BA). O retrato era um presente à 'titia' Carmem, que, enquanto viva, segurou a lembrança com a angústia de quem via o próprio filho se equilibrando à beira de um penhasco. Hoje ela é guardada em uma pasta que Lúcia chama de 'coisas do coração', e carrega em seu verso a tensão e os anseios daquela época expressos em letras de mão”.

III. Youssef Melhem Elkhouri, comerciante.

Para a edição do "Seu Bairro" de 15 de novembro de 2007, Isabela sugeriu que fosse feita uma matéria especial sobre a rua do centro de São José dos Campos que tem aquela data comemorativa como nome. Em busca de moradores que narrassem as histórias da Rua 15 de Novembro, ela chegou ao comerciante mais antigo do local, um libanês que começou a vida no Brasil como mascate e que, aqui, tornou-se um entusiasta da principal festa popular do país.

O texto sobre ele começa dessa maneira: "Quando chegou de navio ao Brasil, em 1951, o libanês Youssef Melhem Elkhouri já tinha uma vaga ideia do que o país tinha a lhe oferecer, pois seus tios e seu pai reportavam a ele, sempre que possível, o que vivenciavam em São José dos Campos - cidade onde se estabeleceram três anos antes em busca de boas oportunidades. $O$ que ele não esperava era que seria tão rapidamente contagiado pela alegria dos Carnavais e por outros tantos contentamentos que ele adora contar (e recontar em questão de minutos) para quem se dispõe a ouvi-lo”.

IV. Alcides Sene, marceneiro e locutor. 
Simãozinho, como Alcides Sene é bem mais conhecido, foi indicado por Paulo César Fernandes, o primeiro dos personagens da série. Isabela já conhecia o trabalho que ele realizava numa rádio local, mas ficou interessada pelo fato de ser uma pessoa "aplaudida" por ouvintes e por entusiastas da música sertaneja, mas, fora dos "holofotes", no dia a dia, viver humildemente, passando basicamente despercebido aos olhos de muita gente. Também chamou sua atenção os muitos cafés que costuma beber durante o dia.

A abertura do texto sobre ele foi estruturada desse modo: "Ser Simãozinho - locutor de rádio, organizador de encontros sertanejos, produtor de discos, marceneiro, vendedor incansável e pai de família - não é tão fácil como podem pensar os muitos ouvintes que, às 5 h, já dão audiência ao programa 'Porteira Sertaneja' da rádio Piratininga. Um dia na vida dele é um misto de bom humor, cansaço e fugas internas turbinados por muitos copinhos de café”.

V. Neusa Fatima de Campos, papiloscopista.

Ser papiloscopista - policial especializado em identificação humana, por meio de impressões digitais - já é motivo para ter muitas histórias para contar. Somado a isso, Neusa Fatima de Campos - ou Xuxa - já foi secretária bilíngue e carrega, no currículo, um curso voltado ao setor hoteleiro, cumprido próximo de completar sessenta anos. Isabela a conheceu ao elaborar uma matéria - especial de domingo, para o primeiro caderno do Valeparaibano - sobre o Centro de Educação Profissional Hélio Augusto de Souza (Cephas), mantido pela Prefeitura de São José, no qual a personagem estudava Turismo e Hotelaria.

O texto inicial foi escrito da seguinte maneira: "Para provar que você é realmente alguém neste mundo é preciso sujar o polegar de tinta preta e pressioná-lo em um espaço branco embaixo de uma fotografia, validando o seu intransferível Registro Geral. Mas para se certificar de que essa e tantas outras identidades são fiéis à realidade, os olhos da papiloscopista Neusa Fatima de Campos, 59 anos, se atentam diariamente por cima de uma lupa estudando cada linha das impressões digitais que são ampliadas pela lente”.

VI. José Aparecido de Oliveira, artista de rua.

Figura conhecida pelas ruas de São José dos Campos, Lunático - nome que o próprio José Aparecido de Oliveira se dá - é um artista de rua, desses que conseguem ser confundidos com o próprio cenário da cidade, tamanha sua inserção no ambiente. Tão comum à própria cidade que faz parte da própria história de Isabela. Ela o vê e acompanha suas graças desde a 
infância, quando ainda estudava num colégio de formação básica. Para muitos, não passa de "um louco do centro". Para outros, é o personagem sonhador que a jornalista retratou.

O parágrafo que abre o texto sobre ele ficou assim: "Logo pela manhã, Lunático se concentra. Com os dois pés bem fixos ao chão, uma de suas pernas começa lentamente a tremer. De repente a energia vai tomando conta do resto do corpo com maior intensidade e o rosto se incha, vermelho, como se fosse explodir. A boca se contrai para não abrir enquanto ele entra em um estado catártico, levantando os braços a 90 graus do corpo. É o 'tremetreme original, tente fazer igual', diz ao relaxar de novo. 'É o meu slogan', emenda.

VII. Johan Guranyi, comerciante.

Foi o único personagem sugerido pelo editor do jornal. Já havia sido fonte de várias matérias no jornal, mas nenhuma que mostrasse, em profundidade, quem de fato é o "João dos Bichos”, apelido que ganhou em razão de seu hobby, no mínimo, curioso: há mais de 35 anos, ele analisa os números sorteados na loteria federal, tendo conquistado bagagem suficiente para explicar quais bichos são mais sorteados e com que frequência. Mas essa é só uma das histórias.

O texto sobre ele tem início assim: "O holandês Johan Guranyi bem que tentou, mas não pôde trocar o sobrenome para o do verdadeiro pai: o pintor Johan Gutlich. Por um erro do hospital em que ele nasceu, em Ameasfoort ['onde só dá gente forte', como brinca], ele carrega o sobrenome do primeiro casamento de sua mãe. Era período pós-guerra quando isso aconteceu, o que justificaria o equívoco. O ano era 1946 e, de lá para cá, muita coisa aconteceu até que ele ficasse conhecido como João dos Bichos".

VIII. Ceci Felicíssima de Moura, aposentada.

Durante a apuração para a matéria especial sobre a Rua 15 de Novembro, mencionada no item III, o fotógrafo que acompanhava Isabela lhe disse que seria interessante captar uma foto panorâmica, a qual precisaria ser tirada do alto. Para tanto, foram até um dos poucos prédios que havia por ali, perguntar se poderiam subir até o terraço para fotografar a via. Ao conversar com o porteiro, a jornalista ficou surpresa com sua rápida resposta: "No último andar vive uma senhora, chamada Ceci. Vou interfonar a ela, e vocês podem subir e tirar a foto de lá". O espanto maior, na verdade, não foi o acesso concedido, sem qualquer objeção, mas a conversa com aquela que se tornaria fonte para a matéria do caderno e, posteriormente, 
personagem do projeto aqui discutido: tratava-se de uma senhora quase centenária - uma das poucas de sua geração -, que vivia sozinha e que aparentava estar visivelmente incomodada com a situação em que se encontrava. Ceci foi a primeira a ser entrevistada para a série, mas faleceu antes de os textos começarem a ser publicados, motivo pelo qual figurou como última personagem do conjunto.

As primeiras linhas de sua descrição apresentam-se nesses termos: "Quando conheci dona Ceci Felicíssima, há dois anos, a felicidade parecia lhe preencher apenas o nome. Em seu magro e cansado corpo, a solidão lhe pesava tanto que andava encolhida, sustentada por uma simples bengala, me dando a sensação de ser ainda mais baixa que seu metro e meio. Tinha 98 anos e morava em um apartamento da rua 15 de novembro aos cuidados de uma moça que, no momento em que cheguei, estava fazendo compras no centro da cidade e cujo namorado não parava de ligar para saber onde estava - o que deixava dona Ceci cada vez mais nervosa. Em algumas horas de conversa fui compreendendo a contradição emocional que é se saber com quase 100 anos: tanta vida para ser contada, ao mesmo tempo em que a angústia do pouco tempo restante é companheira de todas as horas".

É interessante notar que o primeiro contato de Isabela com os personagens da série "Gente de São José” não seguiu padrão nem modelo único. Alguns foram encontrados por acaso, outros por indicação, outros, ainda, pelas próprias circunstâncias do cotidiano ou de seu trabalho como repórter, que lhe deu subsídios para criar um acervo de "pessoas interessantes" e que viabilizou a execução de sua proposta.

\subsection{O desfecho}

Pelo que conseguimos identificar, por meio do diálogo que estabelecemos com a jornalista, a escolha de todos os personagens não atendeu a nenhum outro critério que não o "de interesse", isto é, os selecionados são - mesmo que em escala subjetiva - considerados suficientemente interessantes para figurar numa série como a que ora nos propomos a estudar. Trata-se, evidentemente, de procedimento de escolha orgânico ao próprio processo, que por si só cria situações que inserem ou excluem elementos de seu interior.

“O critério foi, mais ou menos, o meu. Procurei histórias que fossem diferentes entre si, [...] que não fossem conhecidas [...] e que chamassem a atenção por terem um fundo interessante - a resposta para 'Onde é que eu quero chegar com isso? ",, relata Isabela Rosemback. Ela conta que 
buscou identificar, em cada um, esse elemento. No caso de Dona Ceci, por exemplo, o que estava por trás era a experiência de alguém que viveu tanto, viu tantas transformações e sabe que seu próprio fim está próximo; Simãozinho, por outro lado, é o personagem que, apesar de famoso, não costuma ser valorizado por muitos; já Paulo Fernandes é o típico cidadão comum que não demonstra o vasto conhecimento que tem a respeito da história de seu município. "Meu critério era só esse: histórias interessantes de pessoas que a gente nem imagina que tenha", acrescenta a jornalista $^{15}$.

Fator fundamental, além da não interferência do editor na seleção dos personagens - exceto na sugestão de um nome -, foi a liberdade concedida à Isabela para que pudesse escrever com suas próprias características, e não como rezava o manual interno de redação - que embora não fosse formalizado, tal como são os da Folha de S.Paulo, do Estado de S.Paulo e de outros grandes jornais, estabelecia modos de escrita que deveriam ser acatados pelos partícipes do processo de elaboração do veículo.

Também no que concerne à produção dos textos, vale destacar que todos eles demandaram como condição primordial, tempo para apuração. Antes de ir a campo, a repórter estipulou um método básico, que deveria ser utilizado - na medida do possível - com todos os personagens: ela passaria um dia inteiro junto com a fonte, dialogando, conhecendo seus hábitos, percebendo como é sua vida no dia a dia. Assim foi feito. Com algumas exceções - caso do Johan, que não pôde dispor um dia inteiro para esse contato - e algumas adaptações - a Dona Ceci, por exemplo, que, pela idade, se sentiria muito cansada em passar mais de um período concedendo entrevistas, o que fez a jornalista visitá-la em dois dias (em um, durante a manhã, e no outro, na parte da tarde).

Outro aspecto relevante é que Isabela buscou fazer oito materiais diferentes. Nenhum texto é igual ao outro. Todos desvendam particularidades, cenários, situações e outras características singulares de cada sujeito. Além disso, a própria estrutura das páginas era, por vezes, modificada. No texto sobre Simãozinho, por conta de seu hábito de tomar café, a divisão dos itens se deu exatamente em conformidade com o número de cafezinhos tomados durante o dia. Isso nos leva a crer, portanto, que as idiossincrasias de cada personagem ajudaram, conscientemente ou não, a moldar, além do conteúdo, a forma como o texto foi construído, imprimindo-lhe marcas próprias da personalidade de cada entrevistado.

\footnotetext{
${ }^{15}$ Depoimento concedido ao autor em 8 de março de 2012.
} 


\section{Considerações Finais}

Compreendendo as histórias de vida não como classificação textual, mas como “acontecimento jornalístico" (FONSECA \& VIEIRA, 2011, p. 99), ou seja, fatos que têm aptidão para se tornarem material a figurar na imprensa, podemos afirmar que a constituição do gênero e do formato jornalístico, nesse foco, se dá a partir do olhar que o jornalista confere à história por ele apurada e, também, aos interesses do jornal.

Em termos mais específicos, podemos dizer que todos os personagens abordados pela jornalista, na série "Gente de São José”, poderiam ter sido retratados de maneira mais sucinta, com dados específicos e objetivos a respeito de suas trajetórias, sem o mesmo charme e o mesmo interesse que têm as matérias que compõem o corpus deste estudo. Mas aí deixariam de ter o formato que apresentam e, certamente, seriam utilizada para outra finalidade, diferente do que foi proposto pelo projeto.

Por outro lado, devemos nos lembrar de que há embates terminológicos e taxionômicos nesse contexto. Por exemplo: as características dos textos de Isabela Rosemback - as quais podem ser observadas até mesmo nos primeiros parágrafos, reproduzidos há pouco - correspondem ao que denominamos jornalismo diversional e se enquadram no formato que José Marques de Melo classifica como história de interesse humano. Contudo, a jornalista define seu trabalho como sendo produto de jornalismo literário - o que podemos entender como sinônimo para diversional, nesse caso -, mas nomeia as matérias como perfis, os quais, segundo ela, "não têm a pretensão de contar a história de uma pessoa em detalhes. É um recorte da vida dessa pessoa. [...] É um recorte dos momentos mais interessantes ou dos aspectos que eu acredito serem mais importantes"16.

Não esperamos, aqui, modificar essas percepções a respeito do fenômeno, mesmo porque elas se fundamentam em conceitos e em bases tão sólidos quanto as que defendemos. O que pretendemos, com tudo isso, é reforçar o mote de nossa reflexão, exposta logo no título deste trabalho: as histórias de vida aparecem, na esfera dos gêneros jornalísticos, como categoria que reúne certos elementos que podem, guardadas as devidas proporções, colaborar para apresentar a figura humana sob perspectivas até então impensadas, seja por questões comerciais ou pela própria linha editorial do veículo.

Quando bem trabalhados, textos dessa natureza acabam por possibilitar ao leitor o contato com um autêntico jornalismo que se vale dos aspectos literários para revelar a essência da vida, ou

\footnotetext{
${ }^{16}$ Depoimento concedido ao autor em 8 de março de 2012.
} 
seja, o jornalismo diversional. Ou, então, quando necessário, essas mesmas histórias podem somente aparecer como complemento de outros materiais, configurando-se como jornalismo interpretativo. Há espaço para tudo.

\section{Referências}

ASSIS, Francisco de. O gênero jornalístico diversional na imprensa paulista: evidências nos jornais Valeparaibano e Correio Popular. In: CONGRESSO DE CIÊNCIAS DA COMUNICAÇÃO NA REGIÃO SUDESTE, 13., São Paulo, 2008. Anais eletrônicos... São Paulo: Intercom, 2008. BERNAL, Sebastià; CHILLÓN, Luís Albert. Periodismo informativo de creación. Barcelona: Mitre, 1985.

BONINI, Adair. Os gêneros do jornal: o que aponta a literatura da área de comunicação no Brasil? Linguagem em (dis)curso. Tubarão, v. 4, n. 1, p. 205-231, jul./dez. 2003.

DUARTE, Marcia Yukiko Matsuuchi. Estudo de caso. In: DUARTE, Jorge; BARROS, Antônio. (Orgs.). Métodos e técnicas de pesquisa em Comunicação. São Paulo: Atlas, 2005. p. 215-235. FONSECA, Virginia Pradelina da S.; VIEIRA, Karine Moura. A biografia como acontecimento jornalístico. Líbero, São Paulo, v. 14, n. 28, p. 99-108, dez. 2011. GOBBI, Maria Cristina. Método biográfico. In: DUARTE, Jorge; BARROS, Antônio. (Orgs.). Métodos e técnicas de pesquisa em Comunicação. São Paulo: Atlas, 2005. p. 84-97. KOTSCHO, Ricardo. Humanos anônimos. In: BRUM, Eliane. A vida que ninguém vê. Porto Alegre: Arquipélado Editorial, 2006. p. 177-184.

MARQUES DE MELO, José. A práxis inventiva dos gêneros e formatos no jornalismo de Arnon de Mello. In: CONGRESSO BRASILEIRO DE CIÊNCIAS DA COMUNICAÇÃO, 34., Recife, 2011. Anais eletrônicos... São Paulo: Intercom, 2010.

. Panorama diacrônico dos gêneros jornalísticos. In: CONGRESSO BRASILEIRO DE CIÊNCIAS DA COMUNICAÇÃO, 33, Caxias do Sul, 2010. Anais eletrônicos... São Paulo: Intercom, 2010.

. Formatos jornalísticos: evidências brasileiras. Folha de S. Paulo, São Paulo, 28 mar. 2005. 2006a. (Original do autor).

. Gêneros da comunicação de massa: análise dos gêneros e formatos jornalísticos. 2006b.

(Original do autor).

; ASSIS, Francisco de (Orgs.). Gêneros jornalísticos no Brasil. São Bernardo do Campo:

Universidade Metodista de São Paulo, 2010.

NAVA, Rosa Maria Ferreira Dales. Saber para continuar: a história do Departamento de Pesquisa e Documentação do Jornal do Brasil e a implantação pioneira do jornalismo interpretativo no país. 1996. 132 p. Dissertação (Mestrado em Comunicação Social) -Universidade Metodista de São Paulo, São Bernardo do Campo, 1996.

SANTOS, Marli dos. Histórias de vida na grande reportagem: um encontro entre jornalismo e história oral. Comunicação \& Informação, Goiânia, v. 12, n. 2, p. 21-32, jul./dez, 2009.

VILAS BOAS, Sergio. Biografismo: reflexões sobre escritas de vida. São Paulo: Unesp, 2008.

. Perfis: e como escrevê-los. São Paulo: Summus, 2003.

YIN, Robet K. Estudo de caso: planejamento e métodos. 3. ed. Porto Alegre: Bookman, 2005. 